\title{
Spatially-defined motor deficits in people with unilateral complex regional pain syndrome.
}

Emily J Reid ${ }^{\mathrm{a}}$, Sarah B Wallwork ${ }^{\mathrm{a}}$, Daniel Harvie ${ }^{\mathrm{a}, 1} \mathrm{PhD}$, K Jane Chalmers ${ }^{\mathrm{a}, 2}$, Felicity A Braithwaite $^{\mathrm{a}}$, Charles Spence ${ }^{\mathrm{b}} \mathrm{PhD}$, Alberto Gallace ${ }^{\mathrm{c}} \mathrm{PhD}$, G Lorimer Moseley ${ }^{\mathrm{a}, \mathrm{d}} \mathrm{PhD}$ (1)

${ }^{a}$ The Sansom Institute for Health Research, University of South Australia, GPO Box 2471, Adelaide 5000, Australia

${ }^{b}$ Department of Experimental Psychology, University of Oxford, Tinbergen Building, 9 South Parks Road, Oxford, OX1 3UD, England

c University of Milano-Bicocca, Building U6, Room 3038, Piazza dell'Ateneo Nuovo 1, 20126

Milano, Italia

${ }^{d}$ Neuroscience Research Australia, Margarete Ainsworth Building, Barker Street, Randwick NSW 2031, Australia

Author email addresses:

Emily.Reid@unisa.edu.au; $\quad$ wallwork.sarahb@gmail.com; $\quad$ d.harvie@griffith.edu.au; jane.chalmers@unisa.edu.au; felicity.braithwaite@gmail.com; $\quad$ charles.spence@psy.ox.ac.uk;

alberto.gallace1@unimib.it; lorimer.moseley@gmail.com.

\section{Corresponding author:}

Lorimer Moseley

University of South Australia,

1 GPO Box 2471, Adelaide 5000, Australia

T: +61 $883021416, \mathrm{~F}:+61883022853$

E: lorimer.moseley@gmail.com

\footnotetext{
${ }^{1}$ Present address of Dr Daniel Harvie: Menzies Health Institute Queensland, Gold Coast campus, Griffith University, QLD 4222, Australia

${ }^{2}$ Present address of K Jane Chalmers: Western Sydney University, Locked Bag 1797, Penrith NSW 2751
} 


\section{Funding}

2 This work was supported by National Health and Medical Research Council (NHMRC) [grant ID

3 1008017].

4 Miss Reid is a research assistant at Body in Mind.

5 Miss Wallwork was supported by an Australian Postgraduate Award from the Australian

6 Government.

7 Dr Harvie was supported by an Australian Postgraduate Award from the Australian Government.

8 Mrs Chalmers was supported by an Australian Postgraduate Award from the Australian

9 Government.

10 Miss Braithwaite was supported by an Australian Postgraduate Award from the Australian

11 Government.

12 Prof. Moseley was supported by a Principal Research Fellowship from the National Health and

13 Medical Research Council of Australia (NHMRC) ID 1061279.

14

15

16

17

18

19

20

21

22

23

24

25

26 
1 Abstract

2 Objective: Spatially-defined disruption of autonomic and sensory function has been identified in

3 Complex Regional Pain Syndrome (CRPS). This study aimed to determine whether motor

4 performance is also disrupted in a spatially-defined manner in patients with CRPS.

5 Methods: Thirteen patients with CRPS type 1 of the upper limb participated in two motor 6 experiments. In Experiment 1 patients performed a circle drawing task that primarily tested motor 7 accuracy. In Experiment 2 patients performed a button pressing task that tested motor co-ordination.

8 In both experiments the motor tasks were performed with either hand (affected or healthy), and on 9 either side of the body midline - that is, on the affected side of space or healthy side of space.

Results: There was a main effect of both Limb and Side for the motor tasks. In Experiment 1, motor accuracy for the circle drawing task was poorer when patients used their affected hand than when they used their healthy one $(\mathrm{p}<0.001)$, and when the task was performed on the affected side of their body midline than when it was performed on the healthy side $(\mathrm{p}<0.001)$. In Experiment 2 , motor co-ordination for the button pressing task was poorer when patients used their affected hand than when they used their healthy one $(\mathrm{p}<0.001)$, and when the task was performed by either on the affected side of the midline ( $\mathrm{p}<0.001$ ), as compared to the healthy side of the midline.

Conclusions: Unilateral CRPS is associated with a spatially-defined disruption of motor control. Patients perform worse when the task is performed on the affected side of the body midline, regardless of whether they use their affected or healthy hand.

\section{Highlights:}

- We compared the performance of simple motor tasks in people with unilateral CRPS

- Task performance was poorer when using the affected upper limb

- Task performance was poorer on the affected side of space, regardless of hand

- There was a spatial bias towards the healthy side of the body midline

- The findings support the idea of 'somatospatial' neglect in people with CRPS 


\section{Introduction}

2 Complex regional pain syndrome (CRPS) typically develops following a peripheral injury and is

3 characterised by severe pain and dysfunctional autonomic, sensory, endocrine and motor systems

4 (Marinus et al., 2011). Deficits of thermoregulation (Moseley, Gallace, Di Pietro, Spence, \&

5 Iannetti, 2013; G. L. Moseley, A. Gallace, \& G. D. Iannetti, 2012) and tactile processing (Moseley,

6 Gallace, \& Spence, 2009) in upper limb CRPS follow a spatially-defined pattern, implicating

7 parietal integrative function rather than purely somatosensory or autonomic dysregulation. We have

8 recently shown that spatially-defined disruptions in sensory processing in CRPS are only apparent

9 for tasks that involve processing of body-relevant stimuli - the disruption seems to not involve

10 spatial processing as such, but its integration with body-relevant processes. We have proposed that

11 this reflects a kind of 'somatospatial inattention' (Reid et al., 2016). The cortical body matrix

theory, which posits a network of thalamo-cortical loops that subserve the regulation and protection

13 of the body and surrounding space, both physiologically and behaviourally (Moseley, Gallace, \&

14 Spence, 2012), would predict that the motor disturbance associated with CRPS (van Hilten et al.,

15 2011; van Hilten, van de Beek, \& Roep, 2000; van Rijn et al., 2011) should also follow a spatially-

16 defined pattern, but this possibility has not been investigated. We investigated this issue in two

17 experiments in people with unilateral upper limb CRPS. We hypothesised that motor performance

18 of either hand would be poorer when the task was performed with the hand on the affected side of

19 the body midline than when it was performed on the healthy side of the body midline.

\section{2. Materials and methods}

\section{$21 \quad 2.1$ Standard Protocol Approvals and Patient Consents}

22 All experiments conformed to the Declaration of Helsinki. All patients provided written informed consent and ethics approval was granted by the institutional ethics committee. 

9 throughout testing.

\subsection{Sample Size} $\alpha=0.05$.

\subsection{Protocol}

A sample size of 13 was based on detecting a large effect with no drop-outs, $80 \%$ power and

Patients undertook the two experiments in random order. For both experiments, patients sat comfortably with their hands resting on a table in front of them, in a temperature controlled room $\left(21^{\circ} \mathrm{C}-23^{\circ} \mathrm{C}\right)$. There were no windows and one researcher was in the room, behind the patient, 10

\subsubsection{Experiment 1}

Experiment 1 aimed to determine whether, in patients with CRPS, there is an effect of the location of each hand, relative to the body-midline, on the accuracy of a circle drawing task. The primary hypothesis was that accuracy would be modulated by the side of space on which the task was performed. A sheet of white paper was placed in front of the participant, with a vertical line in the middle of the sheet. The sheet midline was aligned with the participant's midline. The experiment involved performance of a circle drawing task, under eight different conditions. Each participant undertook the conditions in a different order, randomized prior to commencement of the study. Prior to each performance, the participants were shown a template of the circle to be drawn (30mm diameter) and its location (130mm lateral to the midline). After 10 seconds, the template was removed and the starting position was obtained with the help of the researcher. The participant was instructed to draw 20 circles sequentially without lifting the pencil from the paper. After the task, they rested for the longer of two minutes or until their pain had returned to pre-task level. In a two by two design, they used either their affected or healthy hand, and drew the circles on the affected or healthy side of the body midline. For performances in which they used their affected hand, they were asked immediately before and immediately after the performance to rate their pain on an 11 
1 point numerical rating scale, anchored with ' $0=$ No pain' and ' $10=$ Worst possible pain'. They

2 performed all four tasks with their eyes open and also with their eyes closed, thus making eight

3 different conditions. There were two primary outcomes. First, we calculated error by measuring the

4 distance between the second innermost circle and the second outermost circle at each of four points

5 of the compass, and averaging them (Fig. 1). This variable was called 'Error'. It has high reliability

$6 \quad($ ICC $=0.92)$ and a small typical error $(<3 \mathrm{~mm})$. Error was used to compare performance between

7 hands and between sides. Second, we calculated the distance (in $\mathrm{mm}$ ) from the beginning of the first

8 circle to the end of the last circle for each performance of the task (Fig. 1). Because we

9 hypothesized a direction-specific effect (toward the healthy side) on this measure during the eyes 10 closed condition, we calculated the horizontal component of the deviation and called it 'Drift'.

\section{INSERT FIGURE 1 ABOUT HERE}

\subsubsection{Statistical Analyses}

All data were calculated, entered and transferred to statistical software (PASW Statistics18, SPSS Inc, Chicago, USA) by each of two investigators who were blinded to the experimental conditions and naïve to the study aims. Final data sets were compared for accuracy. Disagreements were checked and corrected.

To test the primary hypothesis, that motor accuracy would be modulated by the side of space on which the task was performed, we undertook a two (Limb: affected or healthy) x two (Side: affected or healthy) repeated measures ANOVA on the Error scores for the conditions with the eyes open. To test the secondary hypothesis, that motor accuracy would show a neglect-like effect, with a drift toward the healthy side with eyes closed, we undertook a two (Limb: affected or healthy) x two (Side: affected or healthy) x two (Vision: eyes open or eyes closed) repeated-measures ANOVA on 
1 Drift. Because these two analyses interrogate clearly different hypotheses, we did not adjust the $a$

2 priori defined alpha.

3

4 Exploratory analyses investigated whether the Error score for the affected limb on the affected side

5 of space related to average pain in the last two days preceding the experiment, to pre-task pain, or to

6 the duration of CRPS, using univariate regressions. Finally, we investigated whether change in pain

7 during performance of the task with the affected hand was modulated by side, using a two (Time:

8 pre-task and post-task) x two (Side: affected or healthy) repeated-measures ANOVA. Because these

9 analyses were to generate hypotheses for subsequent $a$ priori interrogation, significance was set at $\alpha$

$10=0.05$ and not adjusted for multiple measures.

\subsubsection{Experiment 2}

13 Experiment 2 aimed to determine if the location of each hand relative to the body midline modulates the speed and coordination of a rapid button-pressing task, in participants with unilateral CRPS. The primary hypothesis was that speed and co-ordination of the motor task would be modulated by the side of space on which the task was performed. A custom-made button, mounted on a wooden board, was placed on the table in front of the participant, $12 \mathrm{~cm}$ lateral to the body midline. Participants then completed a rapid button-pressing task, in which they pressed the button as often as they could in $20 \mathrm{~s}$, with their index finger. The task was performed under four conditions: with either hand (affected or healthy), and on either side of the body midline (affected

21 or healthy side of space), the order of which was randomized and counterbalanced. The primary outcome variables were number of button presses, called 'Count', and the standard deviation of the interval between presses, called 'Variability'. 
2 We undertook two ANOVAs. Each was a two (Limb: affected or healthy) x two (Side: affected or

3 healthy) repeated-measures ANOVA on (i) the number of button presses and (ii) the standard 4 deviation of the interval between presses.

5

$6 \quad 3$. Results

$7 \quad 3.1$ Participants

8 Thirteen participants (8 females) who satisfied diagnostic criteria (Bruehl et al., 1999) for CRPS of

9 one arm (Table 1), participated in the two repeated-measures experiments. Six participants had

10 CRPS affecting their left arm. Seven participants had CRPS affecting their dominant limb. Five had

11 also participated in a separate experiment, between three and 13 months earlier (Reid et al., 2016).

12

13

14

15

16

17

18

19

20

21

22

23

24

25

26 
$1 \quad$ Table 1: Participant characteristics

\begin{tabular}{|c|c|c|c|c|c|}
\hline Gender & $\begin{array}{l}\text { Age } \\
\text { (years) }\end{array}$ & $\begin{array}{c}\text { Dominant } \\
\operatorname{limb}\end{array}$ & $\begin{array}{c}\text { Affected } \\
\text { limb }\end{array}$ & $\begin{array}{c}\text { Duration of CRPS } \\
\text { (weeks) }\end{array}$ & $\begin{array}{c}\text { Pain over past two } \\
\text { days (NRS) }\end{array}$ \\
\hline $\bar{F}$ & 25 & $\mathrm{R}$ & $\mathrm{L}$ & 104 & 4 \\
\hline F & 28 & $\mathrm{R}$ & $\mathrm{L}$ & 118 & 6 \\
\hline F & 40 & $\mathrm{R}$ & $\mathrm{L}$ & 93 & 2 \\
\hline F & 40 & L & $\mathrm{L}$ & 280 & 4 \\
\hline F & 42 & $\mathrm{R}$ & $\mathrm{L}$ & 53 & 3 \\
\hline F & 48 & $\mathrm{R}$ & $\mathrm{R}$ & 80 & 4 \\
\hline F & 54 & $\mathrm{R}$ & $\mathrm{L}$ & 170 & 4 \\
\hline F & 62 & $\mathrm{R}$ & $\mathrm{R}$ & 104 & 3 \\
\hline $\mathrm{M}$ & 18 & $\mathrm{R}$ & $\mathrm{R}$ & 135 & 7 \\
\hline $\mathrm{M}$ & 33 & $\mathrm{~L}$ & $\mathrm{R}$ & 262 & 7 \\
\hline $\mathrm{M}$ & 36 & $\mathrm{R}$ & $\mathrm{R}$ & 243 & 3 \\
\hline M & 45 & $\mathrm{R}$ & $\mathrm{R}$ & 201 & 4 \\
\hline M & 56 & $\mathrm{R}$ & $\mathrm{R}$ & 118 & 6 \\
\hline
\end{tabular}

2 F = Female; $\mathrm{M}$ = Male; $\mathrm{R}$ = Right; $\mathrm{L}$ = Left; CRPS = Complex Regional Pain Syndrome; NRS =

3 Numerical Rating Scale where $0=$ No pain and $10=$ Worst possible pain.

4

\section{$5 \quad 3.2$ Experiment 1}

6 Comparing Error across the four conditions in which the eyes were open showed that both Limb

$7 \quad$ (main effect $-\mathrm{F}(1,12)=46.1, \mathrm{p}<0.001)$ and Side $(\mathrm{F}(1,12)=27.2, \mathrm{p}<0.001)$ affected performance on

8 the circle drawing task. There was no interaction $(\mathrm{p}=0.24)$, such that: (i) performance was worse

9 using the affected hand than using the healthy hand, regardless of the side of the midline on which

10 the task was performed, and (ii) performance was worse when the task was performed on the

11 affected side of the midline, regardless of which hand was used (Fig. 2). 
4 Drift towards the healthy side was greater when the task was performed with the affected limb $5 \quad$ (mean $=9.8 \mathrm{~mm},[95 \% \mathrm{CI}]=[5.7-13.9 \mathrm{~mm}])$ than when it was performed with the healthy limb 6 (2.6mm [-3.5 - 8.8mm]), regardless of which side of the body-midline the task was performed, as 7 evidenced by a main effect of $\operatorname{Limb}(F(1,12)=6.74, \mathrm{p}<0.05)$. Drift towards the healthy side was 8 also greater when the task was performed on the affected side of the midline $(10.2 \mathrm{~mm}$ [6.0 $914.4 \mathrm{~mm}])$ than when it was performed on the healthy side of the midline $(2.2 \mathrm{~mm}[-2.9-7.3 \mathrm{~mm}])$, regardless of which hand was used, as evidenced by a main effect of Side $(F(1,12)=20.7$,

$11 \mathrm{p}=0.001)$. A critical result, with respect to the hypothesis, was a Limb $\mathrm{x}$ Side $\mathrm{x}$ Vision interaction, 12 such that, when the participants performed the task with their eyes shut, with their affected hand, and on the affected side of the midline, the mean (95\% CI) drift of the pencil from the start of the first circle to the end of the last, was $25.5 \mathrm{~mm}[18.3-32.6 \mathrm{~mm}]$ towards the healthy side $(\mathrm{F}(1,12)$ =6.18, $\mathrm{p}=0.03$ ). In contrast, Drift during all other conditions was less than 8mm (Fig. 2). For the affected hand in the affected side of space, there was a relationship between motor performance and average pain over the last two days $(\mathrm{r}=0.74$, standardized beta $0.74, \mathrm{p}=0.004)$ and duration of CRPS $(\mathrm{r}=0.57$, standardized beta $0.57, \mathrm{p}=0.04)$, but not to the pre-task pain rating $(p=0.44)$. Finally, pain increased more when the task was performed on the affected side of the 21 midline than when the task was performed on the healthy side of the midline, as evidenced by a Side $x$ Time interaction $(F(1,12)=12.6, p=0.004$; Fig. 3). 


\section{$1 \quad 3.3$ Experiment 2}

2 Comparing the number of button presses between hands and between sides, showed that

3 participants were slower when they used their affected hand (mean [95\% CI] count in 20s $=26$ [19

4 - 33]) than when they used their healthy one 60 [50 - 69]), regardless of side, as evidenced by a

5 main effect of $\operatorname{Limb}(\mathrm{F}(1,12)=64.0, \mathrm{p}<0.001)$. Participants were also slower when they performed

6 the task on the affected side of the body-midline (38 [31 - 45]) than when they performed it on the

7 healthy side (48 [40 - 55]), regardless of which hand they used, as evidenced by a main effect of

8 Side $(\mathrm{F}(1,12)=47.8, \mathrm{p}<0.001$; Fig. 4A). There was no Limb x Side interaction.

9

\section{INSERT FIGURE 4 ABOUT HERE}

Comparing the standard deviations for the interval between button presses, the 'Variability', between limbs and between sides, showed that participants were more variable in their responses when they used their affected hand $(0.35 s[0.16-0.53 \mathrm{~s}])$ than when they used their healthy hand (0.06s [0.05 - 0.07]), regardless of where the task was performed, as evidenced by a main effect of Limb $(F(1,12)=11.6, p=0.05)$. In addition, participants were more variable when they performed the task on the affected side $(0.25 \mathrm{~s}[0.12-0.37 \mathrm{~s}])$ than when they performed it on the healthy side (0.16s $[0.10-0.22 \mathrm{~s}])$, regardless of which hand they used, as evidence by a main effect of Side $(F(1,12)=7.3$, $p=0.02$; Fig. 4B). There was no Limb $x$ Side interaction $(p=0.15)$.

\section{Discussion}

We hypothesised that in upper limb CRPS, motor performance of either hand would be poorer if the tasks were performed with the hand on the affected side of the body midline. Our results support this hypothesis as evidenced by better performance for both the circle drawing task in Experiment 1 and the button pressing task in Experiment 2. These results are important because they confirm that spatially-defined biases exist for motor processing in CRPS. 
2 While investigation of spatially-defined motor deficits is limited in CRPS, the current results

3 corroborate and build upon earlier work by our group and others. Left/right judgments are thought

4 to activate premotor cortices essential for the preparation of movement(Parsons, 2001) and our

5 group has undertaken numerous investigations of implicit motor imagery performance using this

6 paradigm (Bowering, Butler, Fulton, \& Moseley, 2014; Bowering et al., 2013; Dey et al., 2012;

7 McCormick, Zalucki, Hudson, \& Moseley, 2007; Moseley, 2004a; T. Stanton et al., 2012; T. R.

8 Stanton et al., 2013; von Piekartz, Wallwork, Mohr, Butler, \& Moseley, 2015; Wallwork, Butler, \&

9 Moseley, 2013; Wallwork, Butler, Wilson, \& Moseley, 2012). In CRPS, response time for left/right

10 limb judgements of the affected limb is greater than that of their healthy limb (Moseley, 2004b;

11 Schwoebel, Coslett, Bradt, Friedman, \& Dileo, 2002; Schwoebel, Friedman, Duda, \& Coslett, 2001)

12 and there is also a spatially defined effect - responses are slow if they image is displayed on the

13 side of the body midline ipsilateral to the CRPS-affected limb. Critically, no such disruption is

14 evident if the visual stimuli are not body parts (Reid et al., 2016).

The current work extends a growing body of literature showing a spatially-defined imbalance in processing of bodily-related stimuli (Moseley et al., 2013; G. L. Moseley, A. Gallace, \& G. D. Iannetti, 2012; Moseley et al., 2009), and presents compelling evidence that this imbalance also penetrates cortical outputs. There is some precedent for this - disruption of thermoregulation, the feeling of ownership over the limb, and pain are all modulated in CRPS according to the perceived

21 location of the limb relevant to the body midline (Moseley et al., 2013; G. L. Moseley, A. Gallace, \& G. D. Iannetti, 2012). That peripheral signs of CRPS, such as swelling, are also modulated in a spatially defined manner might seem unlikely, but evidence that visual distortion of an affected limb can increase or decrease the swelling evoked by movement, according to whether the visual image is made larger or smaller, (Moseley, Parsons, \& Spence, 2008) clearly shows that top-down modulation of swelling is possible. 
2 Such an impact of top-down mechanisms might be predicted in light of the ubiquitous nature of

3 descending modulatory control of motor mechanisms, from voluntary movements to reflexes

4 (Wallwork, Bellan, Catley, \& Moseley, 2015). For example, the nociception withdrawal reflex is

5 exaggerated in the presence of a disgusting smell (Bartolo et al., 2013) and the hand blink reflex,

6 until recently thought to reflect an automatic brainstem loop, is upregulated if the hand is closer to

7 the face (Sambo, Liang, Cruccu, \& Iannetti, 2012), unless a protective barrier is placed in front of

8 the eyes in which case there is no upregulation at all (Sambo, Forster, Williams, \& Iannetti, 2012).

9 The integration of spatial and somatotopic maps is arguably critical in the processing of most

10 autonomic, sensory and motor information, in that the location of the stimulus and the location of

11 the involved body area would both be important in determining the optimal bodily response.

12 Indeed, brain areas involved in localising a stimulus or physiological event are thought to be critical

13 in the wider multisensory representation that underpins the regulation and protection of our body

14 and peripersonal space (see (G. L. Moseley, A. Gallace, \& C. Spence, 2012)) for review). One

15 difference that emerges within this system, however, relates to understanding whether the stimulus

16 requires involvement of body-related cortical representations. That is, an auditory or visual stimulus

17 can be understood without reference to a bodily representation, unless the stimulus itself is body-

18 related, for example an image of a body part that can only be 'understood' on the basis of whether it

19 belongs to the left or right side of the body.

21 A midline-dependent side-to-side imbalance in only body-relevant tasks and regulatory functions

22 has recently been termed 'somatospatial neglect' (Reid et al., 2016). This is clearly different to the

23 hemispatial neglect that occurs after stroke: post-stroke neglect typically shows a rightward bias and

24 with multiple egocentric and allocentric spatial reference frames involved (Behrmann \& Tipper,

25 1999). Somatospatial neglect in CRPS shows a healthy side bias regardless of left, right, dominant

26 or non-dominant and the processing bias is egocentric, referenced from the body midline, and 
1 directed away from the affected side. Moreover, post-stroke neglect results from brain injury;

2 somatospatial neglect in CRPS does not.

4 Although somatospatial neglect cannot be explained by brain injury, it can be explained by the 5 principles that govern the operation of neural networks (Nicolelis \& Lebedev, 2009). These neural 6 networks (or 'neurotags' (Moseley \& Butler, 2015; Wallwork et al., 2015)) influence each other and 7 cortical outputs such as movement and feelings, according to their precision or reliability, and their

8 synaptic efficacy, both of which are modulated by neuroplasticity. One might predict that complete 9 immobilisation of one hand, protection of the space surrounding the hand by increased visual surveillance, and functional compensation by performing all tasks with the healthy hand on the

11 healthy side of space, would lead to a side-to-side imbalance such as that proposed to underpin 12 somatospatial neglect.

14 Why then, don't all patients with acute CRPS go on to develop these spatially-defined problems? Pain intensity in the first two weeks after injury is a strong predictor of developing acute CRPS (Moseley et al., 2014), but inflammatory response in the acute stage does not differentiate between those who go on to recover and those who do not (Parkitny Submitted). We think that the painamplifying effect of somatospatial neglect raises the possibility that failure to recover might depend on a biological vulnerability for a side-to-side imbalance or the behavioural response to acute CRPS and a 'learnt' side-to-side imbalance, or a combination of both. Clearly, this is a speculative

21 proposal, but it seems worthy of enquiry.

The current work has implications for treatment of CRPS. We have already established that spatially-dependent problems exist in other groups, for example osteoarthritic knee pain (T. Stanton 
1 imagery (GMI), can reduce pain and improve function in CRPS (Bowering et al., 2013). Perhaps

2 refining these therapies and targeting the interdependent relationship between spatial and bodily

3 representations will have even better clinical outcomes for CRPS patients. Further, if we are correct

4 in predicting that disrupted somatospatial processing contributes to a number of different

5 pathological pain conditions, these therapies may be able to improve patient outcomes for these

6 patients too.

8 Our study is not without limitations. Our results are limited to people with CRPS of the upper limb,

9 and the performance of upper limb motor tasks. The motor tasks used in Experiment 1 and

10 Experiment 2 tested motor accuracy and motor co-ordination respectively, but other aspects of

11 movement, such muscle activity patterns, were not assessed. Nonetheless, the current work

12 demonstrates that motor disruption in CRPS is modulated by where, relative to the body midline,

13 the task is performed. The finding is consistent with the idea of somatospatial neglect and raises the 14 possibility of new approaches to CRPS prevention and treatment.

\section{Conclusions}

A spatial bias towards the healthy side of the body midline was evident for upper limb motor tasks performed by participants with CRPS. The results suggest that the midline-centred dysfunction in the processing of tactile input and the regulation of temperature that is present in this population also extends to movement performance. This finding provides further support for the concept of

21 'somatospatial' neglect in people with CRPS. Further investigation of therapies that target the interdependent relationship between spatial and bodily representations in CRPS is warranted. 


\section{Figure captions}

2 Figure 1: Primary Outcomes for Experiment 1. 'Error' was calculated by measuring the distance

3 between the second innermost circle and the second outermost circle at each of four points of the compass $(\mathrm{A}+\mathrm{B}+\mathrm{C}+\mathrm{D})$, and averaging them. 'Drift' was calculated by measuring the horizontal component of the distance from the starting point $\left(\mathrm{X}_{1}\right)$ to the finishing point $\left(\mathrm{X}_{2}\right)$.

Figure 2: Visual Representation of Circle Drawing Task. Error and Drift for the affected limb (A and B) and the healthy limb (C and D), on the affected side of space (A and C) and the healthy side of space (B and D). The Error circles show relative deviation from the template for each hand in either side of space, with eyes closed (blue) and eyes open (red). Error is represented as the mean difference between the inner and outer radii, with the inner radii constant. Drift shows the horizontal component of the distance (in $\mathrm{mm}$ ) from the start of the first circle, to the end of the last circle with eyes open (blue) and eyes closed (red). Error was greatest for the affected limb $\left({ }^{* *} \mathrm{p}<0.001\right)$ and for the affected side of space $\left({ }^{* *} \mathrm{p}<0.001\right)$. Drift was greater for the affected limb $\left({ }^{\wedge} \mathrm{p}<0.05\right)$ and for the affected side of space $(\wedge \mathrm{p}<0.001)$. There was also a Limb $\mathrm{x}$ Side $\mathrm{x}$ Vision interaction for Drift $\left({ }^{*} \mathrm{p}<0.05\right)$.

Figure 3: Pre-task and Post-task Pain for Circle Drawing Task. Pre-task pain (hollow diamond) and post-task pain (filled diamond) on the affected and healthy sides of space. Standard error (error bars) is also shown. Pain increased more when the task was performed on the affected side of the midline than it did when the task was performed on the healthy side of the midline $\left.{ }^{* *} \mathrm{p}=0.004\right)$.

Figure 4: Experiment 2 Button Pressing Task. (A) Count - number of button presses in 20 seconds, and (B) Variability - standard deviation of the interval (in seconds) between button presses shown for the affected limb (hollow diamond), and the healthy limb (filled diamond), on the affected, and on the healthy side of space. The standard deviation (error bars) is also shown. There 
1 was a main effect for both Limb and Side of space for Count, such that there were fewer button

2 presses when the task was performed with the affected $\operatorname{limb}\left({ }^{* *} \mathrm{p}<0.001\right)$, or on the affected side of

3 space $\left({ }^{* *} \mathrm{p}<0.001\right)$. Likewise, there was a main effect for both Limb and Side of space for

4 Variability, such that variability was greater for the affected limb $\left({ }^{*} \mathrm{p}=0.05\right)$, and for the affected

5 side of space $(\wedge \mathrm{p}=0.02)$.

6

\section{References}

Bartolo, M., Serrao, M., Gamgebeli, Z., Alpaidze, M., Perrotta, A., Padua, L., . . . Sandrini, G. (2013). Modulation of the human nociceptive flexion reflex by pleasant and unpleasant odors. Pain, 154(10), 2054-2059. doi: 10.1016/j.pain.2013.06.032

Behrmann, M., \& Tipper, S. P. (1999). Attention accesses multiple reference frames: evidence from visual neglect. J Exp Psychol Hum Percept Perform, 25(1), 83-101.

Bowering, K. J., Butler, D. S., Fulton, I. J., \& Moseley, G. L. (2014). Motor imagery in people with a history of back pain, current back pain, both, or neither. Clin J Pain, 30(12), 1070-1075. doi: 10.1097/AJP.0000000000000066

Bowering, K. J., O'Connell, N. E., Tabor, A., Catley, M. J., Leake, H. B., Moseley, G. L., \& Stanton, T. R. (2013). The effects of graded motor imagery and its components on chronic 
pain: a systematic review and meta-analysis. $J$ Pain, 14(1), 3-13. doi: 10.1016/j.jpain.2012.09.007

Bruehl, S., Harden, R. N., Galer, B. S., Saltz, S., Bertram, M., Backonja, M., . . Stanton-Hicks, M. (1999). External validation of IASP diagnostic criteria for Complex Regional Pain Syndrome and proposed research diagnostic criteria. International Association for the Study of Pain. Pain, 81(1-2), 147-154.

Dey, A., Barnsley, N., Mohan, R., McCormick, M., McAuley, J. H., \& Moseley, G. L. (2012). Are children who play a sport or a musical instrument better at motor imagery than children who do not? [Research Support, Non-U.S. Gov't]. British Journal of Sports Medicine, 46(13), 923-926. doi: 10.1136/bjsports-2011-090525

Marinus, J., Moseley, G. L., Birklein, F., Baron, R., Maihofner, C., Kingery, W. S., \& van Hilten, J. J. (2011). Clinical features and pathophysiology of complex regional pain syndrome. Lancet Neurol, 10(7), 637-648. doi: 10.1016/S1474-4422(11)70106-5

McCormick, K., Zalucki, N., Hudson, M., \& Moseley, G. L. (2007). Faulty proprioceptive information disrupts motor imagery: an experimental study. [Randomized Controlled Trial

Research Support, Non-U.S. Gov't]. The Australian journal of physiotherapy, 53(1), 41-45.

Moseley, G., Gallace, A., \& Iannetti, G. D. (2012). Neglect-like tactile dysfunction in chronic back pain. Neurology, 79, 327-332.

Moseley, G. L. (2004a). Graded motor imagery is effective for long-standing complex regional pain syndrome: a randomised controlled trial. Pain, 108(1-2), 192-198.

Moseley, G. L. (2004b). Why do people with complex regional pain syndrome take longer to recognize their affected hand? Neurology, 62(12), 2182-2186.

Moseley, G. L., \& Butler, D. S. (2015). 15 Years of Explaining Pain - The Past, Present and Future. J Pain, 16(9), 807-813. doi: 10.1016/j.jpain.2015.05.005 
1 Moseley, G. L., Gallace, A., Di Pietro, F., Spence, C., \& Iannetti, G. D. (2013). Limb-specific autonomic dysfunction in complex regional pain syndrome modulated by wearing prism glasses. Pain, 154(11), 2463-2468. doi: 10.1016/j.pain.2013.07.026

Moseley, G. L., Gallace, A., \& Iannetti, G. D. (2012). Spatially defined modulation of skin temperature and hand ownership of both hands in patients with unilateral complex regional pain syndrome. [Research Support, Non-U.S. Gov't]. Brain : a journal of neurology, 135(Pt 12), 3676-3686. doi: 10.1093/brain/aws297

Moseley, G. L., Gallace, A., \& Spence, C. (2009). Space-based, but not arm-based, shift in tactile processing in complex regional pain syndrome and its relationship to cooling of the affected limb. [Research Support, Non-U.S. Gov't]. Brain : a journal of neurology, 132(Pt 11), 31423151. doi: 10.1093/brain/awp224

Moseley, G. L., Gallace, A., \& Spence, C. (2012). Bodily illusions in health and disease: physiological and clinical perspectives and the concept of a cortical 'body matrix'.

Neuroscience and Biobehavioral Reviews, 36(1), 34-46. doi: 10.1016/j.neubiorev.2011.03.013

Moseley, G. L., Herbert, R. D., Parsons, T., Lucas, S., Van Hilten, J. J., \& Marinus, J. (2014). Intense pain soon after wrist fracture strongly predicts who will develop complex regional pain syndrome: prospective cohort study. $J$ Pain, 15(1), 16-23. doi: 10.1016/j.jpain.2013.08.009

Moseley, G. L., Parsons, T. J., \& Spence, C. (2008). Visual distortion of a limb modulates the pain and swelling evoked by movement. Curr Biol, 18(22), R1047-R1048.

Nicolelis, M. A. L., \& Lebedev, M. A. (2009). Principles of neural ensemble physiology underlying the operation of brain-machine interfaces. Nature Reviews. Neuroscience, 10(7), 530-540. doi: http://dx.doi.org/10.1038/nrn2653

Parsons, L. M. (2001). Integrating cognitive psychology, neurology and neuroimaging. Acta Psychologica, 107(1-3), 155-181. 
Reid, E., Wallwork, S. B., Harvie, D., Chalmers, K. J., Gallace, A., Spence, C., \& Moseley, G. L. (2016). A new kind of spatial inattention associated with chronic limb pain? Ann Neurol. doi: 10.1002/ana.24616

Sambo, C. F., Forster, B., Williams, S. C., \& Iannetti, G. D. (2012). To blink or not to blink: fine cognitive tuning of the defensive peripersonal space. The Journal of neuroscience : the official journal of the Society for Neuroscience, 32(37), 12921-12927. doi: 10.1523/JNEUROSCI.0607-12.2012

Sambo, C. F., Liang, M., Cruccu, G., \& Iannetti, G. D. (2012). Defensive peripersonal space: the blink reflex evoked by hand stimulation is increased when the hand is near the face. Journal of Neurophysiology, 107(3), 880-889. doi: 10.1152/jn.00731.2011

Schwoebel, J., Coslett, H. B., Bradt, J., Friedman, R., \& Dileo, C. (2002). Pain and the body schema: Effects of pain severity on mental representations of movement. Neurology, Vol 59(5), 775-777.

Schwoebel, J., Friedman, R., Duda, N., \& Coslett, H. B. (2001). Pain and the body schema: evidence for peripheral effects on mental representations of movement. Brain, 124(Pt 10), 2098-2104.

Stanton, T., Lin, C., Smeets, R., Taylor, D., Law, R., \& Moseley, G. (2012). Spatially-defined disruption of motor imagery performance in people with osteoarthritis. Rheumatology, 51(8), 1455-1464.

Stanton, T. R., Lin, C. W., Bray, H., Smeets, R. J., Taylor, D., Law, R. Y., \& Moseley, G. L. (2013). Tactile acuity is disrupted in osteoarthritis but is unrelated to disruptions in motor imagery performance. Rheumatology (Oxford), 52(8), 1509-1519. doi: 10.1093/rheumatology/ket139

van Hilten, J. J., Munts, A. G., Mugge, W., Meurs, T. S., Schouten, A. C., Marinus, J., . . van der Helm, F. C. T. (2011). Fixed Dystonia in Complex Regional Pain Syndrome: a Descriptive and Computational Modeling Approach. Bmc Neurology, 11. doi: Artn 53 
Doi 10.1186/1471-2377-11-53

van Hilten, J. J., van de Beek, W. J., \& Roep, B. O. (2000). Multifocal or generalized tonic dystonia of complex regional pain syndrome: a distinct clinical entity associated with HLA-DR13. Ann Neurol, 48(1), 113-116.

van Rijn, M. A., Marinus, J., Putter, H., Bosselaar, S. R., Moseley, G. L., \& van Hilten, J. J. (2011). Spreading of complex regional pain syndrome: not a random process. [Research Support, Non-U.S. Gov't]. Journal of Neural Transmission, 118(9), 1301-1309. doi: 10.1007/s00702011-0601-1

von Piekartz, H., Wallwork, S. B., Mohr, G., Butler, D. S., \& Moseley, G. L. (2015). People with chronic facial pain perform worse than controls at a facial emotion recognition task, but it is not all about the emotion. J Oral Rehabil, 42(4), 243-250. doi: 10.1111/joor.12249

Wallwork, S. B., Bellan, V., Catley, M. J., \& Moseley, G. L. (2015). Neural representations and the cortical body matrix: implications for sports medicine and future directions. $\mathrm{Br} J$ Sports Med. doi: 10.1136/bjsports-2015-095356

Wallwork, S. B., Butler, D. S., \& Moseley, G. L. (2013). Dizzy people perform no worse at a motor imagery task requiring whole body mental rotation; a case-control comparison. Frontiers in human neuroscience, 7, 258. doi: 10.3389/fnhum.2013.00258

Wallwork, S. B., Butler, D. S., Wilson, D. J., \& Moseley, G. L. (2012). Are people who do yoga any better at a motor imagery task than those who do not? British Journal of Sports Medicine. doi: 10.1136/bjsports-2012-091873 